\title{
External validation of the Scandinavian guidelines for management of minimal, mild and moderate head injuries in children
}

Johan Undén ${ }^{16,17}$, Stuart R. Dalziel ${ }^{11,12}$, Meredith L. Borland ${ }^{4,5}$, Natalie Phillips ${ }^{6}$, Amit Kochar ${ }^{7}$, Mark D. Lyttle ${ }^{2,13,14}$, Silvia Bressan ${ }^{2,15}$, John A. Cheek ${ }^{1,2,9}$, Jocelyn Neutze ${ }^{10}$, Susan Donath ${ }^{2,3}$, Stephen Hearps ${ }^{2}$, Ed Oakley ${ }^{1,2,3}$, Sarah Dalton ${ }^{8}$, Yuri Gilhotra ${ }^{6}$, Franz E. Babl ${ }^{1,2,3^{*}}$ and on behalf of the Paediatric Research in Emergency

Departments International Collaborative (PREDICT)

\begin{abstract}
Background: Clinical decision rules (CDRs) aid in the management of children with traumatic brain injury (TBI). Recently, the Scandinavian Neurotrauma Committee (SNC) has published practical, evidence-based guidelines for children with Glasgow Coma Scale (GCS) scores of 9-15. This study aims to validate these guidelines and to compare them with other CDRs.

Methods: A large prospective cohort of children ( $<18$ years) with TBI of all severities, from ten Australian and New Zealand hospitals, was used to assess the SNC guidelines. Firstly, a validation study was performed according to the inclusion and exclusion criteria of the SNC guideline. Secondly, we compared the accuracy of SNC, CATCH, CHALICE and PECARN CDRs in patients with GCS 13-15 only. Diagnostic accuracy was calculated for outcome measures of need for neurosurgery, clinically important TBI (ciTBI) and brain injury on CT.

Results: The SNC guideline could be applied to 19,007/20,137 of patients (94.4\%) in the validation process. The frequency of ciTBI decreased significantly with stratification by decreasing risk according to the SNC guideline. Sensitivities for the detection of neurosurgery, ciTBI and brain injury on CT were 100.0\% (95\% Cl 89.1-100.0; 32/32), 97.8\% (94.5-99.4; 179/183) and 95\% (95\% Cl 91.6-97.2; 262/276), respectively, with a CT/admission rate of 42\% (mandatory CT rate of 5\%, 18\% CT or admission and $19 \%$ only admission). Four patients with ciTBI were missed; none needed specific intervention. In the homogenous comparison cohort of 18,913 children, the SNC guideline performed similar to the PECARN CDR, when compared with the other CDRs.
\end{abstract}

Conclusion: The SNC guideline showed a high accuracy in a large external validation cohort and compares well with published CDRs for the management of paediatric TBI.

Keywords: Head trauma, Head injury, Guideline, Clinical decision rule, Infant, Child, Computed tomography, Scandinavia

\section{Background}

Traumatic brain injury (TBI) is a major global health problem [1] with a general incidence of 262 per 100,000 per year [2], which does not seem to be declining despite increased knowledge and prevention strategies [3]. TBI is common in

\footnotetext{
* Correspondence: franz.babl@rch.org.au

'Department of Emergency Medicine, Royal Children's Hospital, 50

Flemington Rd, Parkville, Victoria 3052, Australia

${ }^{2}$ Murdoch Children's Research Institute, Melbourne, 50 Flemington Rd,

Parkville, Victoria 3052, Australia

Full list of author information is available at the end of the article
}

both developed and also in low- and middle-income countries and is associated with considerable mortality and morbidity $[3,4]$. The incidence of TBI is higher in children than in adults [5], children are often more difficult to assess and neuroradiological management is associated with concerning health risks [6, 7].

Initial management is focused on the detection or exclusion of significant brain injury, in particular injuries that would need neurosurgical procedures. The gold-standard investigation is computed tomography $(\mathrm{CT})$, which reliably detects and excludes intracranial complications following

(c) The Author(s). 2018 Open Access This article is distributed under the terms of the Creative Commons Attribution 4.0 International License (http://creativecommons.org/licenses/by/4.0/), which permits unrestricted use, distribution, and 
head injury. However, the concerns of economic, logistic and radiation burden of increasing $\mathrm{CT}$ use limits its use for all children with head injury [8-11]. An alternative option is admission to hospital of intermediate risk groups for clinical observation with deferred CT imaging if signs and symptoms worsen or do not improve, a practice which has been demonstrated to be safe but may be associated with higher health care costs $[12,13]$.

Clinical decision rules (CDRs) have been developed to stratify patients according to the risk of important outcomes and hence indication for CT, with the goal of optimising resource use while assuring detection of important intracranial injuries. Several CDRs for children have been developed including the Pediatric Emergency Care Applied Research Network (PECARN) rule, the Canadian Assessment of Tomography for Childhood Head Injury (CATCH) rule and the Children's Head Injury Algorithm for the Prediction of Important Clinical Events (CHALICE) rule [14-16]. These were derived using high-quality methods and have recently been externally validated in a large prospective cohort [17]. Although the PECARN rule seems to display the best accuracy [17], in particular a very high sensitivity for relevant outcomes, the actual impact of such a rule will depend on the target population and baseline management routines. Although not borne out by recent data $[18,19]$, there is an ongoing concern that these rules may increase CT use in some settings [20].

Recently, the Scandinavian Neurotrauma Committee (SNC), a non-profit organisation of neurosurgeons, anaesthesiologists, intensivists, neurologists and other specialties from Sweden, Norway, Denmark, Finland and Iceland, with an interest in TBI, developed and published evidence-based guidelines for management of minimal, mild and moderate head injuries in adults [21] and children [20]. These guidelines offer a comprehensive guide to TBI management, including selection of patients for CT scan and/or hospital observation, in the context of the Scandinavian health care system, see Fig. 1. As these guidelines were not based on a derivation cohort, validation, in particular external validation, is required before widespread clinical implementation.

Recently, Babl et al. published an appropriately powered multicentre validation and comparison study, the Australian Paediatric Head Injury Rules Study (APHIRST), comparing the accuracy of the PECARN, CHALICE and CATCH CDRs $[17,22]$. This study included sufficient predictor variables to externally validate the SNC guidelines. In addition to an external validation as the primary aim, we set out to compare the SNC guidelines to the PECARN, CHALICE and CATCH CDRs.

\section{Methods}

\section{Design and setting}

The APHIRST study was a prospective multicentre observational study, which enrolled 20,137 children (age $<18$ years) with head injury of all severities at ten Australian and New Zealand centres of the Paediatric Research in Emergency Departments International Collaborative (PREDICT) network [23]. Predictor variables from the PECARN, CATCH and CHALICE were collected, and the performance accuracy of these rules was externally validated. Detailed information on this study can be found in the primary publication [16] and the protocol publication [22].

The SNC guideline is intended for all children $(<18$ years $)$ with head injury and a GCS of 9-15, presenting within $24 \mathrm{~h}$ of injury [20]. Being a tool for selecting children for imaging, those children who have already had imaging are excluded.

\section{Procedure}

In most cases, the clinical predictors elicited in the APHIRST study were identical to the ones used in the SNC guideline. In the few instances where variables were different, assumptions were made a priori to analysis, see Table 1. SNC guideline parameters were applied to the APHIRST dataset, and suggested management was noted.

As with the APHIRST parent publication [17], the SNC guideline was assessed in two ways. Firstly, the cohort was inputted into the SNC guideline according to the guideline inclusion criteria and with the intended SNC primary outcomes, neurosurgical intervention and intracranial injury [20]. Secondly, the same comparison cohort used in the parent publication [17], i.e. children with a GCS of 13-15 who presented within $24 \mathrm{~h}$ of injury, was used in order to compare the SNC guideline with PECARN, CHALICE and CATCH CDRs. The common outcome variable used to compare the accuracy of the SNC guideline and the three CDRs was the presence of clinically important TBI (ciTBI) [14].

\section{Definitions}

Neurosurgery was defined as any neurosurgical procedure for TBI.

ciTBI was defined according to the PECARN definition; death from TBI, neurosurgical intervention for TBI, intubation of more than $24 \mathrm{~h}$ from TBI or hospital admission of two nights or more for TBI, associated with TBI on CT [14].

TBI on CT was defined as any acute intracranial finding revealed on CT that was attributable to acute injury, including closed depressed skull fractures and pneumocephalus, but excluding non-depressed skull fractures and basilar skull fractures [14].

As the SNC guideline recommends both CT and/or hospital admission with observation, depending on the 


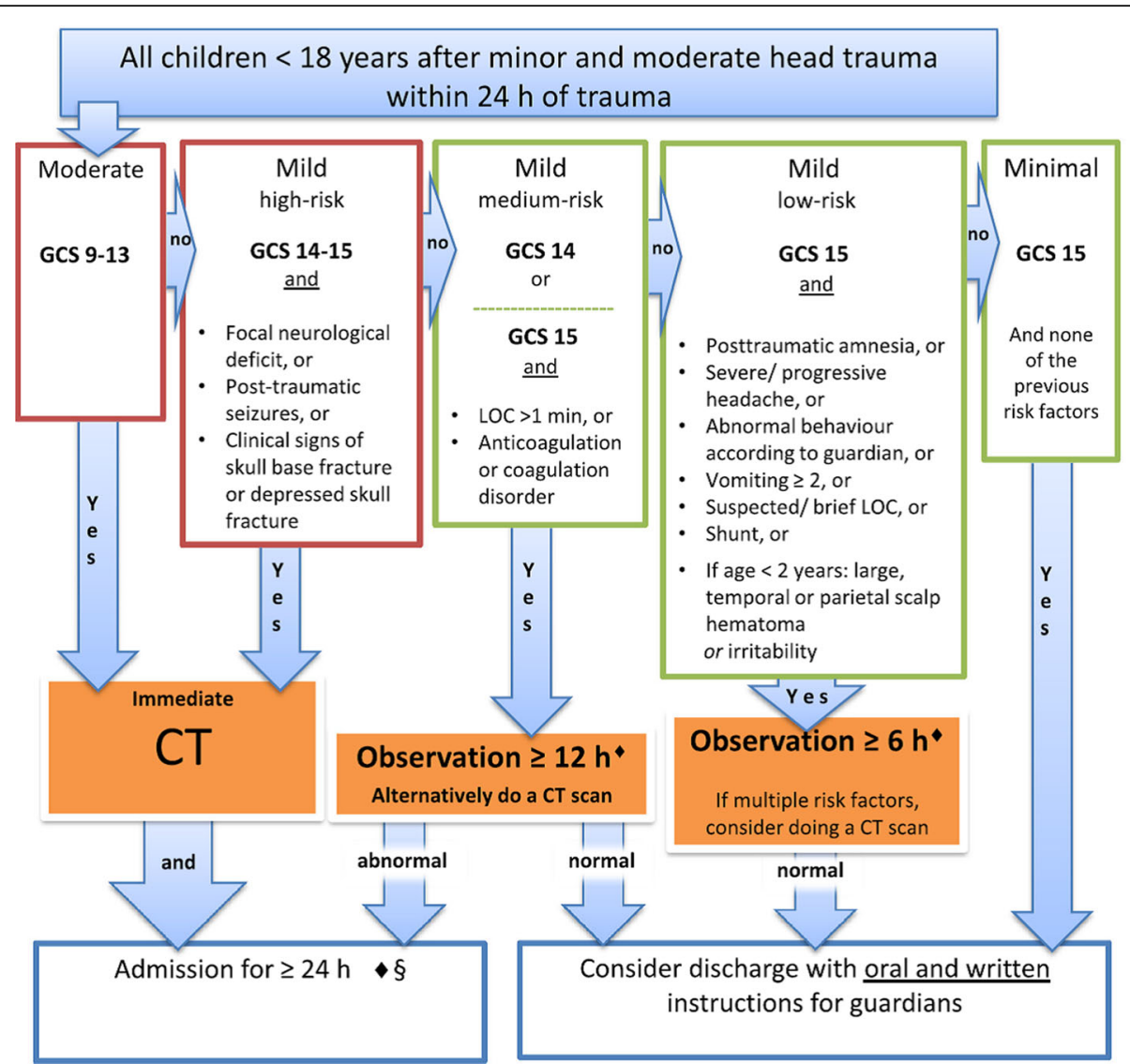

Fig. 1 The Scandinavian Neurotrauma Committee (SNC) guideline for management of children $(<18$ years) with minimal, mild and moderate traumatic brain injury (TBI) [20]. GCS Glasgow Come Scale, LOC loss of consciousness, CT computed tomography. Modified from Astrand et al. [20]

risk group, a binary variable was assumed where CT and/or observation was compared to discharge. This is similar to the method used for the external validation of the PECARN rule [17].

\section{Analysis}

We did not undertake a separate sample size calculation beyond the sample size calculation undertaken for the APHIRST parent study [22].

Sensitivity, specificity and predictive values were calculated with corresponding 95\% confidence intervals. Differences between risk groups were assessed by Fisher's exact test.

\section{Results}

From the original sample of 20,137 children, we applied SNC guideline eligibility criteria and excluded 1013 children who presented $>24 \mathrm{~h}$ after injury and 117 with GCS $<9$. Therefore, a total of 19,007 children $(94 \%$ of the total cohort) were applicable to the SNC guideline. Selected patient characteristics are shown in Table 2.

\section{Validation of SNC guideline}

Thirty-two $(0.17 \%)$ children needed neurosurgery, 183 (1.0\%) had ciTBI, 276 (1.5\%) had a TBI on CT and one patient died (TBI was not the cause of death in this patient). The distribution of children in the different SNC risk categories, with corresponding neurosurgery, ciTBI and brain injury on CT outcomes, is shown in Fig. 2. There were significant differences between the risk groups in terms of ciTBI frequency. When combining groups to represent the recommendations of 'immediate $\mathrm{CT}$,' 'observation or $\mathrm{CT}$, 'observation' and 'discharge,' there were also highly significant differences, see Fig. 2. In the primary analysis of the SNC guideline, point sensitivities for the detection of neurosurgery, ciTBI and TBI on CT were 100, 98 and $95 \%$, respectively, and point specificities were 58,59 and $59 \%$, respectively (Table 3 ).

\section{SNC guideline comparison with CDRs}

Of 18,913 children included in the comparison cohort, we further omitted patients with a GCS of 9-12. Twenty-four $(0.13 \%)$ children needed neurosurgery, 160 (0.85\%) had ciTBI, 251 (1.3\%) had TBI on CT and one patient died. Point sensitivities and specificities for the 
Table 1 Comparison of inclusion criteria, exclusion criteria and clinical predictors between the Australasian Paediatric Head Injury Rules Study (APHIRST) cohort and the Scandinavian Neurotrauma Committee (SNC) guidelines

\begin{tabular}{|c|c|}
\hline APHIRST & SNC \\
\hline \multicolumn{2}{|l|}{ Inclusion criteria } \\
\hline All children $<18$ years, all GCS & All children $<18$ years with head injury within $24 \mathrm{~h}$ of trauma, GCS 9-15 \\
\hline \multicolumn{2}{|l|}{ Exclusion criteria } \\
\hline Trivial facial injury only & Prior imaging \\
\hline \multicolumn{2}{|l|}{ Referral from ER to external provider } \\
\hline \multicolumn{2}{|l|}{ Neuroimaging before transfer to site } \\
\hline \multicolumn{2}{|l|}{ Did not wait to be seen } \\
\hline \multicolumn{2}{|l|}{ Predictor variables } \\
\hline GCS 9-13 & GCS 9-13 \\
\hline GCS 14 & GCS 14 \\
\hline Positive focal neurology & Focal neurological deficit \\
\hline Seizure in patient with no history of epilepsy & Post-traumatic seizures \\
\hline $\begin{array}{l}\text { (Clinical signs of basal skull fracture) OR (suspicion of penetrating } \\
\text { or depressed skull injury) }\end{array}$ & Clinical signs of skull base fracture or depressed skull fracture \\
\hline $\mathrm{LOC}>5 \mathrm{~s}$ & $\mathrm{LOC}>1 \mathrm{~min}$ \\
\hline Any bleeding disorder or anticoagulation therapy & Anticoagulation or coagulation disorder \\
\hline Amnesia (antegrade or retrograde; $>5$ min) & Post-traumatic amnesia \\
\hline (Severe headache) OR (history of worsening headache) & Severe/progressive headache \\
\hline Not acting normally per parent report & Abnormal behaviour according to guardian \\
\hline Vomiting $\geq 2$ episodes & Vomiting $\geq 2$ episodes \\
\hline Any or suspected LOC & Suspected/brief LOC \\
\hline Shunt & Shunt \\
\hline $\begin{array}{l}\text { (Age }<2 \text { and irritability on examination) OR (age }<2 \text { and temporal } \\
\text { or parietal hematoma) OR (age }<2 \text { and large, boggy scalp hematoma) }\end{array}$ & If age $<2$ years, large, temporal or parietal scalp hematoma OR irritability \\
\hline Combination of at least two risk factors from the SNC predictors & Multiple risk factors \\
\hline
\end{tabular}

GCS Glasgow Come Scale, ER emergency room, LOC loss of consciousness

detection of neurosurgery, ciTBI and TBI on CT were similar to the validation cohort (Table 4). Four patients with ciTBI and 14 with TBI on CT were missed by the SNC guideline (Table 5). All the missed ciTBIs were classified as such due to admission to hospital $>2$ days for TBI, with none needing any specific intervention.

\section{$\mathrm{CT}$ and observation rate}

Applying the SNC guideline would have resulted in a CT/in-hospital observation rate of $42 \%$ in both the validation sample and in the comparison cohort. When strictly applied, the mandatory $\mathrm{CT}$ rate for the SNC guideline (Fig. 1) would have been only $5 \%$ in both the validation and comparison cohorts, with an $18 \%$ rate of observation or CT and a $19 \%$ rate for only observation (no CT). If children with multiple risk factors and medium-risk factors (observation or $\mathrm{CT}$ according to the guideline) were all to receive a $\mathrm{CT}$, the rate would be $23 \%$.

\section{Discussion}

In this study, we were able to apply a multinational clinical head injury guideline from Scandinavia to a large, previously collected data set of head injured children and externally assess the accuracy of the guideline. This study appears to adequately validate the accuracy of the SNC guidelines for the management of minimal, mild and moderate head injury in children. In the validation cohort, the guideline displayed a high sensitivity for important outcomes, missing four patients with ciTBI, 14 patients with TBI on CT scan, but no patients requiring neurosurgery out of over 19,000 patients. The SNC guideline was designed to be a pragmatic and universal aid [20]; as demonstrated by the large number of patients, the guideline could be applied to the current APHIRST cohort. Only patients with severe head injury, those who already had neuroimaging and those seeking medical care after $24 \mathrm{~h}$ are excluded by the guideline.

When comparing the applicability of the SNC guideline with well-known CDRs, when used as designed [24], 
Table 2 Patient characteristics in the entire Australasian Paediatric Head Injury Rules Study (APHIRST) cohort, the APHIRST comparison cohort and the patients eligible for the Scandinavian Neurotrauma Committee (SNC) guideline

\begin{tabular}{|c|c|c|c|}
\hline & $\begin{array}{l}\text { APHIRST validation } \\
n=20,137\end{array}$ & $\begin{array}{l}\text { APHIRST comparison } \\
n=18,913\end{array}$ & $\begin{array}{l}\text { SNC } \\
n=19,007\end{array}$ \\
\hline \multicolumn{4}{|l|}{ DEMOGRAPHICS } \\
\hline Mean age & $5.7(\mathrm{sd} 4.7)$ & 5.7 (sd 4.6) & $5.7(\mathrm{sd} 4.6)$ \\
\hline$<2$ years & $5374(26.7 \%)$ & 5046 (26.7\%) & $5067(26.7 \%)$ \\
\hline$\geq 2$ years & $14,763(73.3 \%)$ & $13,867(73.3 \%)$ & $13,940(73.3 \%)$ \\
\hline Boys & $12,828(63.7 \%)$ & $12,073(63.8 \%)$ & $12,136(63.9 \%)$ \\
\hline Girls & 7309 (36.3\%) & $6840(36.2 \%)$ & $6871(36.1 \%)$ \\
\hline \multicolumn{4}{|l|}{ Injury mechanism } \\
\hline Fall & $14,119(70.1 \%)$ & $13,337(70.5 \%)$ & $13,401(70.5 \%)$ \\
\hline Motor vehicle incident & $849(4.2 \%)$ & $745(3.9 \%)$ & $759(4.0 \%)$ \\
\hline High-impact projetile or object & $1320(6.6 \%)$ & $1228(6.5 \%)$ & $1232(6.5 \%)$ \\
\hline Suspected non-accidental injury & $112(0.6 \%)$ & $81(0.4 \%)$ & $85(0.4 \%)$ \\
\hline High-energy/velocity trauma & $1669(8.3 \%)$ & $1523(8.1 \%)$ & $1543(8.1 \%)$ \\
\hline \multicolumn{4}{|l|}{ Predictor examples } \\
\hline GCS3-8 & $121(0.6 \%)$ & - & - \\
\hline GCS 9-13 & $231(1.2 \%)$ & $132(0.7 \%)$ & $226(1.2 \%)$ \\
\hline GCS 14 & $578(2.9 \%)$ & $567(3.0 \%)$ & $567(3.0 \%)$ \\
\hline GCS 15 & $19,207(95.4 \%)$ & $18,214(96.3 \%)$ & $18,214(95.8 \%)$ \\
\hline LOC & $2707(13.5 \%)$ & $2468(13.0 \%)$ & $2506(13.2 \%)$ \\
\hline Vomiting & $3452(17.1 \%)$ & $3094(16.4 \%)$ & $3138(16.5 \%)$ \\
\hline Headache & $4127(20.5 \%)$ & $3785(20.0 \%)$ & $3810(20.0 \%)$ \\
\hline Multiple risk factors & $2597(12.9 \%)$ & $2324(12.3 \%)$ & $2359(12.4 \%)$ \\
\hline \multicolumn{4}{|l|}{ Outcomes } \\
\hline Cranial CT & $2106(10.5 \%)$ & $1691(8.9 \%)$ & $1760(9.3 \%)$ \\
\hline Admission & $4544(22.6 \%)$ & $4164(22.0 \%)$ & $4229(22.2 \%)$ \\
\hline ER discharge & $15,594(77.4 \%)$ & $14,749(78.0 \%)$ & $14,778(77.8 \%)$ \\
\hline Neurosurgery & $83(0.4 \%)$ & $24(0.1 \%)$ & $32(0.2 \%)$ \\
\hline Death & $15(0.1 \%)$ & $1(<0.01 \%)$ & $1(<0.01 \%)$ \\
\hline Clinically important TBI (PECARN) & $280(1.4 \%)$ & $160(0.8 \%)$ & $183(1.0 \%)$ \\
\hline Clinically significant intracranial injury (CHALICE) & $403(2.0 \%)$ & $251(1.3 \%)$ & $276(1.5 \%)$ \\
\hline
\end{tabular}

GCS Glasgow Come Scale, ER emergency room, LOC loss of consciousness, CT computed tomography, TBI traumatic brain injury, PECARN Paediatric Emergency Care Applied Research Network, CHALICE Children's Head Injury Algorithm for the Prediction of Important Clinical Events, NS neurosurgery, ciTBI clinically important traumatic brain injury, sd standard deviation

the SNC guideline was applicable to a high percentage of the patient cohort (94\%); similar to the CHALICE rule $(99.5 \%)$, a rule including all severities of head injury, and more inclusive than the CATCH $(24.6 \%)$ and PECARN rules (75.3\%) [17]. Adherence to clinical guidelines and CDRs may be problematic [25, 26], especially when dealing with specific and multiple inclusion criteria for guideline applicability [24]. A pragmatic guideline with near-universal inclusion is therefore desirable to ensure clinical use as intended.

Comparing guidelines is difficult due to the differing inclusion criteria, clinical predictors and outcome variables used. Using the APHIRST dataset, a comparison cohort (identical to the SNC inclusion criteria with the exception of patients with GCS 9-12) could be used to directly compare the accuracy of the different rules. The performance of the SNC guideline was similar to the PECARN CDR (high sensitivity, lower specificity) rather than the CATCH and CHALICE CDRs (lower sensitivities but higher specificities). However, the confidence intervals overlap, meaning a statistical difference cannot formally be established. Nonetheless, for the outcome of neurosurgery (the primary outcome variable of the SNC guideline and arguably the most important outcome variable in TBI $[17,20])$, the SNC guideline was $100 \%$ sensitive, with a relatively high lower 95\% confidence 


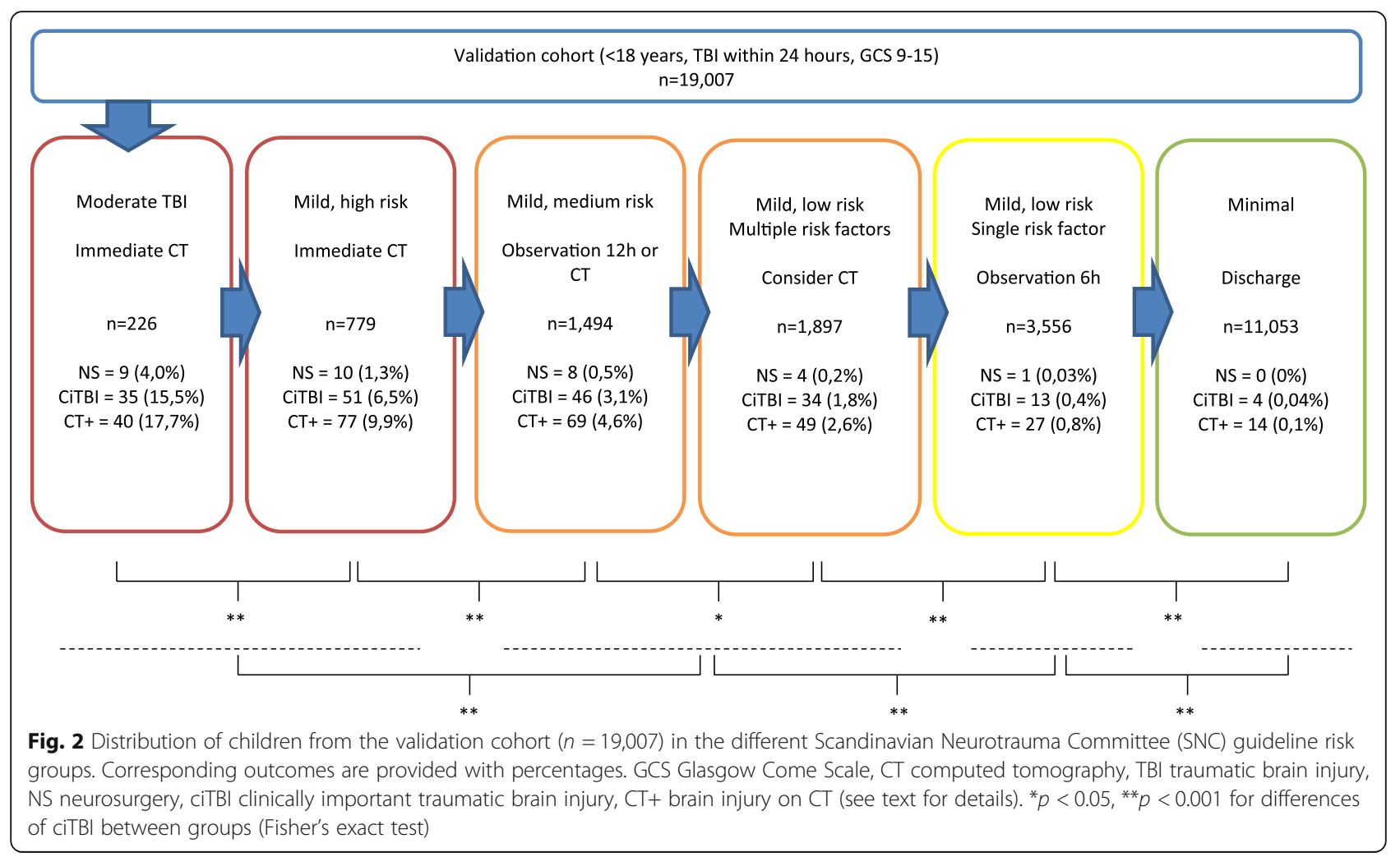

interval (85.8\%) and a higher overall specificity than PECARN. As an evidence-based guideline, the largest individual evidence contributor for the synthesis of the SNC guideline was derived from the PECARN study, which likely explains the similarities in performance.

The projected CT or admission rate for SNC of $42 \%$, in both the validation and comparison sample, is difficult to compare with the CATCH or CHALICE CDRs. Both dichotomise patients into $\mathrm{CT} /$ no $\mathrm{CT}$, without consideration of observation, with projected $\mathrm{CT}$ rates for $\mathrm{CATCH}$ of $30 \%$ (using all predictors) and for the CHALICE rule of $22 \%$, for the comparison cohorts. However, as with the PECARN CDR [14], the SNC guideline has both a CT and in-hospital observation management option, depending on the risk group. The rate for mandatory CT (moderate or high-risk mild TBI according to the guidelines) was only $5 \%$, which increases to $23 \%$ if children with medium-risk mild TBI or multiple risk factors (observation or $\mathrm{CT}$ according to the guideline) were all to receive a $\mathrm{CT}$.

No patients requiring neurosurgery would be discharged according to the SNC guideline. One patient needing neurosurgery was assigned to the 6-h inhospital observation group and another 12 patients needing neurosurgery to the in-hospital observation or CT groups. The present study did not include necessary details to examine if the SNC observation routines, mandating a CT scan when a fall in GCS or new/progressive

Table 3 Performance of the Scandinavian Neurotrauma Committee (SNC) guidelines in the validation cohort $(n=19,007)$

\begin{tabular}{llll}
\hline Outcome & Neurosurgery $^{a}$ & CiTBI $^{a}$ & Brain injury on CT $^{a}$ \\
\hline SNC CT or observation, with outcome & 32 & 179 & 262 \\
SNC CT or observation, without outcome & 7921 & 7775 & 7692 \\
SNC discharge, with outcome & 0 & 4 & 14 \\
SNC discharge, without outcome & 11,052 & 11,049 & 11,039 \\
Sensitivity (95\% Cl) & $100 \%(89.1-100)$ & $97.8 \%(94.5-99.4)$ & $94.9 \%(91.6-97.2)$ \\
Specificity (95\% Cl) & $58.3 \%(57.5-59.0)$ & $58.7 \%(58.0-59.4)$ & $58.9 \%(58.2-59.6)$ \\
PPV (95\% Cl) & $0.4 \%(0.3-0.6)$ & $2.3 \%(1.9-2.6)$ & $3.3 \%(2.9-3.7)$ \\
NPV (95\% Cl) & $100 \%(100-100)$ & $100 \%(99.9-100)$ & $99.9 \%(99.8-99.9)$ \\
\hline
\end{tabular}

CT computed tomography, $P P V$ positive predictive value, NPV negative predictive value, ciTBI clinically important traumatic brain injury 
Table 4 Performance of the PECARN, CATCH, CHALICE and SNC guidelines in the comparison cohort with all children presenting within 24 h of injury and GCS 13-15 $(n=18,913)$

\begin{tabular}{|c|c|c|c|c|c|c|c|c|c|c|c|c|c|}
\hline \multirow{5}{*}{ Primary outcome } & \multicolumn{4}{|l|}{ PECARN } & \multirow{3}{*}{\multicolumn{3}{|c|}{ CATCH }} & \multirow{3}{*}{\multicolumn{3}{|c|}{ CHALICE }} & \multirow{3}{*}{\multicolumn{3}{|c|}{ SNC }} \\
\hline & \multirow{2}{*}{\multicolumn{2}{|c|}{$\begin{array}{l}<2 \text { years } \\
n=5046\end{array}$}} & \multirow{2}{*}{\multicolumn{2}{|c|}{$\frac{2 \text { years }}{n=13,867}$}} & & & & & & & & & \\
\hline & & & & & & & & & & & & & \\
\hline & & & & & & & & & & & & & \\
\hline & Positive & Negative & Positive & Negative & & Positive & Negative & & Positive & Negative & & Positive & Negative \\
\hline \multirow{2}{*}{$\begin{array}{l}\text { Clinically important } \\
\text { traumatic brain injury * }\end{array}$} & Yes 42 & 0 & Yes 117 & 1 & Yes & 147 & 13 & Yes & 148 & 12 & Yes & 156 & 4 \\
\hline & No 2047 & 2957 & No 6606 & 7143 & No & 5560 & 13,193 & No & 4018 & 14,735 & No 7 & 7704 & 11,049 \\
\hline \multirow[t]{2}{*}{ Sens $(95 \% \mathrm{Cl})$} & \multicolumn{2}{|l|}{$42 / 42$} & \multicolumn{2}{|l|}{$117 / 118$} & \multicolumn{3}{|c|}{$147 / 160$} & \multicolumn{3}{|c|}{$148 / 160$} & \multicolumn{3}{|c|}{$156 / 160$} \\
\hline & \multicolumn{2}{|c|}{$100.0 \%(91.6-100.0)$} & \multicolumn{2}{|c|}{$99 \cdot 2 \%(95 \cdot 4-100 \cdot 0)$} & \multicolumn{3}{|c|}{$91.9 \%(86.5-95 \cdot 6)$} & \multicolumn{3}{|c|}{$92.5 \%(87.3-96 \cdot 1)$} & \multicolumn{3}{|c|}{$97.5 \%(93.7-99.3)$} \\
\hline \multirow[t]{2}{*}{ Spec (95\% Cl) } & \multicolumn{2}{|l|}{$2957 / 5004$} & \multicolumn{2}{|l|}{$7143 / 13749$} & \multicolumn{3}{|c|}{$13,193 / 18753$} & 14,73 & $35 / 18753$ & & $11,04 \varsigma$ & 49/18753 & \\
\hline & $59 \cdot 1 \%(57 \cdot 7-6$ & 50.5) & $52.0 \%(51 \cdot 1-5$ & 2.8) & $70 \cdot 49$ & $\%(69 \cdot 7-7$ & 71.0) & $78.6 \%$ & $\%(78.0-7$ & (9.2) & $58.9 \%$ & $\%(58.2-5$ & 59.6) \\
\hline PPV (95\% Cl) & $42 / 2089$ & & $117 / 6723$ & & $147 /$ & 5707 & & $148 / 4$ & 4166 & & $156 / 7$ & 7860 & \\
\hline & $2.0 \%(1.5-2.7)$ & & $1.7 \%(1 \cdot 4-2 \cdot 1)$ & & $2 \cdot 6 \%$ & $(2 \cdot 2-3 \cdot 0)$ & & $3.6 \%$ & $(3 \cdot 0-4 \cdot 2)$ & & $2.0 \%$ & $(1.7-2.3)$ & \\
\hline NPV $(95 \% \mathrm{Cl})$ & $2957 / 2957$ & & $7143 / 7144$ & & 13,19 & $93 / 13206$ & & 14,73 & $35 / 14747$ & & $11,04 \varsigma$ & 49/11053 & \\
\hline & $100.0 \%$ (99.9- & $-100 \cdot 0)$ & $100.0 \%(99.9$ & 100.0) & 99.99 & $\%(99 \cdot 8-9$ & $99.9)$ & $99.9 \%$ & $\%(99 \cdot 9-1$ & 00.0) & $100 \%$ & $6(99 \cdot 9-10$ & 00.0) \\
\hline Secondary outcomes & & & & & & & & & & & & & \\
\hline & Positive & Negative & Positive & Negative & & Positive & Negative & & Positive & Negative & & Positive & Negative \\
\hline Traumatic brain injury & Yes 70 & 0 & Yes 180 & 1 & Yes & 220 & 31 & Yes & 227 & 24 & Yes 2 & 237 & 14 \\
\hline & No 2019 & 2957 & No 6543 & 7143 & No & 5487 & 13,175 & No & 3939 & 14,723 & No 7 & 7623 & 11,039 \\
\hline Sens $(95 \% \mathrm{Cl})$ & $70 / 70$ & & 180/181 & & $220 /$ & 251 & & $227 / 2$ & 251 & & $237 / 2$ & 251 & \\
\hline & $100.0 \%(94.9-$ & $-100 \cdot 0)$ & $99.4 \%(97.0-1$ & $00 \cdot 0)$ & $87 \cdot 69$ & $\%(82.9-9$ & 1.5) & $90 \cdot 4 \%$ & $\%(86 \cdot 1-9$ & 3.8) & $94.4 \%$ & $\%(90.8-9$ & 96.9) \\
\hline Spec $(95 \%$ Cl) & $2957 / 4976$ & & $7143 / 13686$ & & 13,17 & 75/18662 & & 14,72 & 23/18662 & & 11,035 & 39/18662 & \\
\hline & $59.4 \%(58.0-6$ & 50.8) & $52 \cdot 2 \%(51 \cdot 4-5$ & 3.0) & $70 \cdot 69$ & $\%(69.9-7$ & 71.3) & $78.9 \%$ & $\%(78 \cdot 3-7$ & 9.5) & $59.2 \%$ & $\%(58.4-5)$ & 59.9) \\
\hline PPV (95\% Cl) & $70 / 2089$ & & $180 / 6723$ & & $220 /$ & 5707 & & $227 / 2$ & 4166 & & $237 / 7$ & 7860 & \\
\hline & $3.4 \%(2 \cdot 6-4 \cdot 2)$ & & $2 \cdot 7 \%(2 \cdot 3-3 \cdot 1)$ & & $3.9 \%$ & $(3 \cdot 4-4 \cdot 4)$ & & $5.4 \%$ & $(4 \cdot 8-6 \cdot 2)$ & & $3.0 \%$ & $(2.6-3.4)$ & \\
\hline NPV $(95 \%$ Cl) & $2957 / 2957$ & & $7143 / 7144$ & & 13,17 & 75/13206 & & 14,72 & 23/14747 & & 11,039 & $39 / 11053$ & \\
\hline & $100.0 \%$ (99.9- & $-100 \cdot 0)$ & $100.0 \%$ (99.9- & 100.0) & 99.80 & $\%(99.7-9$ & 99.8) & $99.8 \%$ & $\%(99 \cdot 8-9$ & 9.9) & $99.9 \%$ & $\%(99.8-9)$ & 99.9) \\
\hline & Positive & Negative & Positive & Negative & & Positive & Negative & & Positive & Negative & & Positive & Negative \\
\hline Neurosurgery* & Yes 6 & 0 & Yes 180 & & Yes & 23 & 1 & Yes & 22 & 2 & Yes 2 & 24 & 0 \\
\hline & No 2083 & 2957 & No 6705 & 7144 & No & 5684 & 13,205 & No & 4144 & 14,745 & No 7 & 7835 & 11,052 \\
\hline Sens $(95 \% \mathrm{Cl})$ & $6 / 6$ & & $18 / 18$ & & $23 / 2$ & & & $22 / 2$ & & & $24 / 24$ & & \\
\hline & $100 \cdot 0 \%(54 \cdot 1-$ & $-100 \cdot 0)$ & $100.0 \%(81.5-$ & 100.0) & $95 \cdot 8$ & $\%(78.9-9$ & $99.9)$ & $91.7 \%$ & $\%(73 \cdot 0-9$ & 9.0) & 100.0 & \% (85.8- & $-100.0)$ \\
\hline Spec (95\% Cl) & $2957 / 5040$ & & $7144 / 13849$ & & 13,2 & $05 / 18889$ & & 14,74 & 45/18889 & & 11,052 & $52 / 18889$ & \\
\hline & $58.7 \%(57 \cdot 3-6$ & 50.0) & $51 \cdot 6 \%(50 \cdot 7-5$ & 2.4) & 69.99 & $\%(69 \cdot 2-7$ & 70.6) & $78.1 \%$ & $\%(77 \cdot 5-7$ & 8.6) & $58.5 \%$ & $\%(57.8-5)$ & 59.2) \\
\hline PPV (95\% Cl) & $6 / 2089$ & & $18 / 6723$ & & $23 / 5$ & 707 & & $22 / 4$ & 166 & & $24 / 78$ & 859 & \\
\hline & $0.3 \%(0.1-0.6)$ & & $0.3 \%(0.2-0.4)$ & & $0.4 \%$ & $(0.3-0.6)$ & & $0.5 \%$ & $(0.3-0.8)$ & & $0.3 \%$ & $(0.2-0.5)$ & \\
\hline NPV $(95 \%$ Cl) & 2957/2957 & & $7144 / 7144$ & & $13,2 C$ & $05 / 13206$ & & 14,74 & 45/14747 & & 11,052 & $52 / 11052$ & \\
\hline & $100.0(99.9-10$ & 00.0) & 100.0\% (99.9- & 100.0) & $100 \cdot c$ & \%\% (100.0 & -100.0) & $100 \cdot 0$ & \%\% (100.0 & $-100 \cdot 0)$ & 100.0 & \% (100.0 & $-100 \cdot 0)$ \\
\hline
\end{tabular}

PECARN Paediatric Emergency Care Applied Research Network, CATCH Canadian Assessment of Tomography for Childhood Head Injury, CHALICE Children's Head Injury Algorithm for the Prediction of Important Clinical Events, Sens sensitivity, Spec specificity, PPV positive predictive value, NPV negative predictive value ${ }^{\mathrm{a}} \mathrm{See}$ text for detailed definitions

neurological symptoms are observed, would have led to a prompt CT scan for these patients. Children are not to be discharged from hospital until their symptoms (i.e. clinical predictors) have resolved [20]. Overall, this approach may be more expensive than a CT option [13], but removes the logistics and potential radiation risks associated with $\mathrm{CT}$ scans.

The corresponding numbers for mandatory $\mathrm{CT}$ for the PECARN CDR are not known, though the $\mathrm{CT}$ rate 
Table 5 Characteristics of patients with Glasgow Come Score (GCS) 13-15 presenting within 24 h after injury in the comparison cohort with clinically important traumatic brain injury (CiTBI) not identified by Scandinavian Neurotrauma Committee (SNC) guideline

\begin{tabular}{|c|c|c|c|c|c|c|}
\hline Age & Gender & GCS & $\begin{array}{l}\text { Mechanism of } \\
\text { injury }\end{array}$ & Injury recorded on CT & Neurosurgery & $\begin{array}{l}\text { Clinically important } \\
\text { traumatic brain injury }\end{array}$ \\
\hline \multirow[t]{2}{*}{6 years } & \multirow[t]{2}{*}{$\mathrm{F}$} & \multirow[t]{2}{*}{15} & \multirow[t]{2}{*}{ Fall $1.5 \mathrm{~m}-3 \mathrm{~m}$} & \multirow{2}{*}{$\begin{array}{l}\text { Intracranial haemorrhage/contusion—extra-axial } \\
\text { Pneumocephalus } \\
\text { Skull fracture-non depressed }\end{array}$} & \multirow[t]{2}{*}{ No } & Yes \\
\hline & & & & & & Admitted $>2$ days \\
\hline \multirow[t]{2}{*}{10 years } & \multirow[t]{2}{*}{$\mathrm{F}$} & \multirow[t]{2}{*}{15} & \multirow{2}{*}{$\begin{array}{l}\text { Fall from } \\
\text { motorised vehicle }\end{array}$} & \multirow{2}{*}{$\begin{array}{l}\text { Intracranial haemorrhage/contusion-extra-axial and } \\
\text { parenchymal Pneumocephalus } \\
\text { Basilar skull fracture }\end{array}$} & \multirow[t]{2}{*}{ No } & Yes \\
\hline & & & & & & Admitted $>2$ days \\
\hline \multirow[t]{2}{*}{15 years } & \multirow[t]{2}{*}{ M } & \multirow[t]{2}{*}{15} & \multirow[t]{2}{*}{ Unclear } & \multirow[t]{2}{*}{ Intracranial haemorrhage/contusion—-parenchymal } & \multirow[t]{2}{*}{ No } & Yes \\
\hline & & & & & & Admitted $>2$ days \\
\hline \multirow[t]{2}{*}{2 years } & \multirow[t]{2}{*}{ M } & \multirow[t]{2}{*}{15} & \multirow{2}{*}{$\begin{array}{l}\text { Kicked by } \\
\text { animal }\end{array}$} & \multirow{2}{*}{$\begin{array}{l}\text { Intracranial contusion—-parenchymal } \\
\text { Depressed skull fracture }\end{array}$} & \multirow[t]{2}{*}{ No } & Yes \\
\hline & & & & & & Admitted $>2$ days \\
\hline
\end{tabular}

CT computed tomography

would probably be higher due to presence of GCS 14 and altered mental status as predictors for mandatory $\mathrm{CT}$. The presence of these risk factors was a major issue when the SNC workgroup were deciding on the adaptation of an external guideline (PECARN) or synthesising a new, evidence-based guideline. We chose to use the latter strategy, as the group found GCS 14 to be too unreliable as a risk factor to recommend a mandatory CT [27-29] and altered mental status too complicated to use effectively, with potential to lead to unacceptable increases in CT rates in Scandinavia. For this reason, allowing an element of physician judgement in the medium-risk group was chosen.

Unlike other guidelines, the SNC stratifies patients into multiple risk groups for important outcomes. This allows physicians to further understand the potential impact of management in patients. Our analysis confirms the stratification, with higher risk groups showing significantly higher rates of important outcome, such as ciTBI, with gradual reduction of these rates with decreasing risk Fig. 2.

High-energy trauma mechanism is not a strict risk factor in the SNC guidelines. These patients are relatively uncommon in Scandinavia and are managed according to separate clinical trauma protocols. Most receive CT scanning and all of these children are admitted. This risk factor was also judged as complicated to use, having a specific definition and often including assessment of fall height, vehicle speed and number of stairs. In the validation cohort, 1543 patients were involved in high-energy trauma, 65 had brain injury on CT, 50 had ciTBI and 9 needed neurosurgery. All patients needing neurosurgery were identified by other predictors included in the SNC guideline. This suggests that omitting this risk factor is safe in the presence of other risk factors included in the guideline.

Children with suspicion of non-accidental injury (NAI) are always admitted to hospital in Scandinavia and generally receive diagnostic imaging. However, this is not a defined risk factor in the actual guideline, although it is clearly stated that these children should be admitted independent of TBI predictors [20].

In adult TBI management, biomarkers, specifically $\mathrm{S} 100 \mathrm{~B}$, have been recommended in clinical guidelines as they could reduce CT rates and overall costs [30] and studies in children have shown promise [31]. Such a biomarker would be most valuable in the intermediate risk groups, such as the medium- and low-risk groups from the SNC guidelines (i.e. the groups presently managed with in-hospital observation), especially considering that today's clinical predictors seem to have reached their full potential for decision making. Indeed, the actual CT rate from the APHIRST study was only $8.9 \%$ in the comparison cohort [17], indicating that clinical guidelines may have limited effect in situations with high-baseline clinician accuracy and low CT rates [32]. However, the evidence base for $\mathrm{S} 100 \mathrm{~B}$ is too weak for a clinical recommendation in children. Other potential biomarkers have shown promise in adults [33], but studies in children are lacking.

Ultimately, the choice of a guideline will be dependent on the baseline situation and intended effect in the health care setting. Before the SNC guideline, most Swedish hospitals did not have official management pathways for paediatric head injury [34] and many used the SNC guideline from 2000 [13], intended for adults. Although the PECARN rules are based upon a rigorously powered cohort and are externally validated, Scandinavian experts were reluctant to recommend these rules for clinical practice, instead opting for a pragmatic, universal and comprehensive evidence-based option [20]. The results of this study support this approach.

The main strength of this study is the large dataset which was robustly powered and prospectively collected. Also, the dataset was adopted into the guideline by an author $(\mathrm{SH})$ unconnected with the SNC group. However, a limitation is that the dataset was not designed with the 
SNC guidelines in mind (published first after the study was commenced), but to assess the accuracy of PECARN, CHALICE and CATCH. Clinical predictors were, however, identical in most cases. The few cases where clinical predictors were approximated would likely not have affected the overall performance of the guideline. Additionally, the clinical setting was that of Australian and New Zealand emergency predominately tertiary departments, which may differ from care in the Scandinavian countries for which the SNC guideline was developed.

\section{Conclusion}

In this study, we were able to apply the clinical SNC head injury guideline to a large, previously collected data set of head injured children. The evidence-based SNC head injury guideline was externally assessed in terms of its accuracy and found to have a high sensitivity, missing very few patients with ciTBI and none needing neurosurgery. The present validation study supports the clinical use of the guideline, although national validation in Scandinavian countries may also be warranted.

\section{Abbreviations}

CATCH: Canadian Assessment of Tomography for Childhood Head Injury; CDR: Clinical Decision Rule; CHALICE: Children's Head Injury Algorithm for the Prediction of Important Clinical Events; ciTBI: Clinically important TBI; CT: Computed tomography; PECARN: Pediatric Emergency Care Applied Research Network; PREDICT: Paediatric Research in Emergency Departments International Collaborative; SNC: Scandinavian Neurotrauma Committee; TBI: Traumatic brain injury

\section{Acknowledgements}

We would like to thank all the participating centres for the collection of data.

\section{Funding}

This present study was funded by non-commercial Swedish state sources Region Skåne and Region Halland, Sweden.

The APHIRST parent study was funded by grants from the National Health and Medical Research Council (project grant GNT1046727, Centre of Research Excellence for Paediatric Emergency Medicine GNT1058560), Canberra, Australia; the Murdoch Children's Research Institute, Melbourne, Australia; the Emergency Medicine Foundation (EMPJ-11162), Brisbane, Australia; Perpetual Philanthropic Services (2012/1140), Australia; Auckland Medical Research Foundation (No. 3112011) and the A + Trust (Auckland District Health Board), Auckland, New Zealand; WA Health Targeted Research Funds 2013, Perth, Australia; the Townsville Hospital and Health Service Private Practice Research and Education Trust Fund, Townsville, Australia; and supported by the Victorian Government's Infrastructure Support Program, Melbourne, Australia. FEB's time was part funded by a grant from the Royal Children's Hospital Foundation, Melbourne, Australia, an NHMRC Practitioner Fellowship GNT1124466 and a Melbourne Children's Clinician Scientist Fellowship. SRD's time was part funded by the Health Research Council of New Zealand (HRC13/556).

\section{Availability of data and materials}

Original datasets are available in [17] or else may be supplied upon discussion with the senior author (FB).

\section{Authors' contributions}

$\mathrm{SH}$ did the data calculations, and the results were overviewed by JU. JU drafted the manuscript with input from all authors. All other authors collected the data. All authors have approved the final manuscript.

\section{Ethics approval and consent to participate}

The study was approved by the institutional ethics committees at each participating site (Royal Children's Hospital (31008R); Princess Margaret (2025/EP); Kids First Starship Children's Hospital (13/NTA/22/AM02); Royal Children's Hospital Brisbane, Mater Children's Hospital and The Townsville Hospital (HREC/12/QRCH/58); Women's and Children's Hospital (HREC/13/WCHN/14); Children's Hospital Westmead (LNR/13/SCHN/43); and Monash Medical Centre (12326B). We obtained informed verbal consent from parents, guardians or older adolescents (as per local ethics requirements) apart from instances of lifethreatening or fatal injuries where participating ethics committees granted a waiver of consent [22]

Consent for publication

Not applicable

\section{Competing interests}

The authors declare that they have no competing interests.

\section{Publisher's Note}

Springer Nature remains neutral with regard to jurisdictional claims in published maps and institutional affiliations.

\section{Author details}

'Department of Emergency Medicine, Royal Children's Hospital, 50 Flemington Rd, Parkville, Victoria 3052, Australia. 'Murdoch Children's Research Institute, Melbourne, 50 Flemington Rd, Parkville, Victoria 3052, Australia. ${ }^{3}$ Department of Paediatrics, Faculty of Medicine, Dentistry and Health Sciences, University of Melbourne, Melbourne, Grattan St, Parkville, Victoria 3010, Australia. ${ }^{4}$ Emergency Department, Princess Margaret Hospital for Children, Roberts Rd, Subiaco, Perth, Western Australia 6008, Australia. ${ }^{5}$ Divisions of Paediatrics and Emergency Medicine, School of Medicine, University of Western Australia, 35 Stirling Hwy, Crawley, Western Australia 6009, Australia. ${ }^{6}$ Emergency Department, Lady Cilento Children's Hospital, Brisbane and Child Health Research Centre, School of Medicine, The University of Queensland, 501 Stanley St, South Brisbane, Queensland 4101 Australia. 'Emergency Department, Women's \& Children's Hospital, Adelaide, 72 King William St, North Adelaide, South Australia 5006, Australia. ${ }^{8}$ Emergency Department, The Children's Hospital at Westmead, 212 Hawkesbury Rd, Westmead, New South Wales 2145, Australia. ${ }^{9}$ Emergency Department, Monash Medical Centre, 246 Clayton Rd, Clayton, Victoria 3186, Australia. ${ }^{10}$ Emergency Department, Kidzfirst Middlemore Hospital, 100 Hospital Rd, Auckland 2025, New Zealand. ${ }^{11}$ Emergency Department, Starship Children's Health, 2 Park Rd, Grafton, Auckland 1023, New Zealand. ${ }^{12}$ Liggins Institute, University of Auckland, 85 Park Ave, Grafton, Auckland 1023, New Zealand. ${ }^{13}$ Emergency Department, Bristol Children's Hospital, Paul O'Gorman Building, Upper Maudlin St, Bristol BS2 8BJ, UK. ${ }^{14}$ Academic Department of Emergency Care, University of the West of England, Blackberry Hill, Bristol BS16 1XS, UK. ${ }^{15}$ Department of Women's and Children's Health, University of Padova, Via Giustiniani3, 2, 35128 Padova, Padova, Italy. ${ }^{16}$ Department of Operation and Intensive Care, Hallands Hospital, Halmstad, Sweden. ${ }^{17}$ Lund University, Lund, Sweden.

Received: 12 June 2018 Accepted: 7 September 2018

Published online: 12 October 2018

\section{References}

1. Maas Al, Stocchetti N, Bullock R. Moderate and severe traumatic brain injury in adults. Lancet Neurol. 2008;7(8):728-41.

2. Peeters W, van den Brande R, Polinder S, Brazinova A, Steyerberg EW, Lingsma HF, et al. Epidemiology of traumatic brain injury in Europe. Acta Neurochir. 2015;157(10):1683-96.

3. Maas AIR, Menon DK, Adelson PD, Andelic N, Bell MJ, Belli A, InTBIR Participants and Investigators, et al. Traumatic brain injury: integrated approaches to improve prevention, clinical care, and research. Lancet Neurol. 2017;16(12):987-1048.

4. Hyder AA, Wunderlich CA, Puvanachandra P, Gururaj G, Kobusingye OC. The impact of traumatic brain injuries: a global perspective. NeuroRehabilitation. 2007;22(5):341-53

5. McKinlay A, Grace RC, Horwood LJ, Fergusson DM, Ridder EM, MacFarlane MR. Prevalence of traumatic brain injury among children, adolescents and 
young adults: prospective evidence from a birth cohort. Brain Inj. 2008;22(2): 175-81.

6. Brenner DJ, Hall EJ. Computed tomography_an increasing source of radiation exposure. N Engl J Med. 2007;357(22):2277-84.

7. Mathews JD, Forsythe AV, Brady Z, Butler MW, Goergen SK, Byrnes GB, et al. Cancer risk in 680,000 people exposed to computed tomography scans in childhood or adolescence: data linkage study of 11 million Australians. BMJ. 2013;346:f2360.

8. Larson DB, Johnson LW, Schnell BM, Goske MJ, Salisbury SR, Forman HP. Rising use of $C T$ in child visits to the emergency department in the United States, 1995-2008. Radiology. 2011;259(3):793-801.

9. Sodickson A, Baeyens PF, Andriole KP, Prevedello LM, Nawfel RD, Hanson R, et al. Recurrent $C T$, cumulative radiation exposure, and associated radiationinduced cancer risks from CT of adults. Radiology. 2009;251(1):175-84.

10. Pearce MS, Salotti JA, Little MP, McHugh K, Lee C, Kim KP, et al. Radiation exposure from $C T$ scans in childhood and subsequent risk of leukaemia and brain tumours: a retrospective cohort study. Lancet. 2012;380(9840):499-505.

11. Miglioretti DL, Johnson E, Williams A, Greenlee RT, Weinmann S, Solberg LI, et al. The use of computed tomography in pediatrics and the associated radiation exposure and estimated cancer risk. JAMA Pediatr. 2013;167(8): 700-7.

12. af Geijerstam JL, Oredsson S, Britton M, Study Investigators OCTOPUS. Medical outcome after immediate computed tomography or admission for observation in patients with mild head injury: randomised controlled trial. BMJ. 2006;333(7566):465.

13. Ingebrigtsen T, Romner B, Kock-Jensen C. Scandinavian guidelines for initial management of minimal, mild, and moderate head injuries. Scand Neurotrauma Comm J Trauma. 2000;48(4):760-6.

14. Kuppermann N, Holmes JF, Dayan PS, Hoyle JD Jr, Atabaki SM, Holubkov R, et al. Identification of children at very low risk of clinically-important brain injuries after head trauma: a prospective cohort study. Lancet. 2009; 374(9696):1160-70.

15. Osmond MH, Klassen TP, Wells GA, Correll R, Jarvis A, Joubert G, et al. CATCH: a clinical decision rule for the use of computed tomography in children with minor head injury. CMAJ. 2010;182(4):341-8.

16. Dunning J, Daly JP, Lomas JP, Lecky F, Batchelor J, Mackway-Jones K, et al. Derivation of the children's head injury algorithm for the prediction of important clinical events decision rule for head injury in children. Arch Dis Child. 2006;91(11):885-91.

17. Babl FE, Borland ML, Phillips N, Kochar A, Dalton S, McCaskill M, et al. Accuracy of PECARN, CATCH, and CHALICE head injury decision rules in children: a prospective cohort study. Lancet. 2017;389(10087):2393-402.

18. Bressan S, Romanato S, Mion T, Zanconato S, Da Dalt L. Implementation of adapted PECARN decision rule for children with minor head injury in the pediatric emergency department. Acad Emerg Med. 2012;19(7):801-7.

19. Nigrovic LE, Stack AM, Mannix RC, Lyons TW, Samnaliev M, Bachur RG, et al. Quality improvement effort to reduce cranial CTs for children with minor blunt head trauma. Pediatrics. 2015;136(1):e227-33.

20. Astrand R, Rosenlund C, Unden J, Scandinavian Neurotrauma Committee (SNC). Scandinavian guidelines for initial management of minor and moderate head trauma in children. BMC Med 2016;14:33-016-0574.

21. Unden J, Ingebrigtsen T, Romner B, Scandinavian Neurotrauma Committee (SNC). Scandinavian guidelines for initial management of minimal, mild and moderate head injuries in adults: an evidence and consensus-based update. BMC Med 2013;11:50-7015-11-50.

22. Babl FE, Lyttle MD, Bressan S, Borland M, Phillips N, Kochar A, et al. A prospective observational study to assess the diagnostic accuracy of clinical decision rules for children presenting to emergency departments after head injuries (protocol): the Australasian Paediatric Head Injury Rules Study (APHIRST). BMC Pediatr. 2014;14:148. https://doi. org/10.1186/1471-2431-14-148.

23. Babl F, Borland M, Ngo P, Acworth J, Krieser D, Pandit S, et al. Paediatric Research in Emergency Departments International Collaborative (PREDICT): first steps towards the development of an Australian and New Zealand research network. Emerg Med Australas. 2006;18(2):143-7.

24. Lyttle MD, Cheek JA, Blackburn C, Oakley E, Ward B, Fry A, et al. Applicability of the CATCH, CHALICE and PECARN paediatric head injury clinical decision rules: pilot data from a single Australian centre. Emerg Med J. 2013;30(10):790-4.

25. Gupta A, Ip IK, Raja AS, Andruchow JE, Sodickson A, Khorasani R. Effect of clinical decision support on documented guideline adherence for head CT in emergency department patients with mild traumatic brain injury. J Am Med Inform Assoc. 2014;21(e2):e347-51.

26. Stiell IG, Bennett C. Implementation of clinical decision rules in the emergency department. Acad Emerg Med. 2007;14(11):955-9.

27. Gill M, Martens K, Lynch EL, Salih A, Green SM. Interrater reliability of 3 simplified neurologic scales applied to adults presenting to the emergency department with altered levels of consciousness. Ann Emerg Med. 2007; 49(4):403-7, 407.e1.

28. Gill MR, Reiley DG, Green SM. Interrater reliability of Glasgow Coma Scale scores in the emergency department. Ann Emerg Med. 2004;43(2):215-23.

29. Bledsoe BE, Casey MJ, Feldman J, Johnson L, Diel S, Forred W, et al. Glasgow Coma Scale scoring is often inaccurate. Prehosp Disaster Med. 2015;30(1):46-53.

30. Calcagnile O, Anell A, Unden J. The addition of S100B to guidelines for management of mild head injury is potentially cost saving. BMC Neurol. 2016;16(1):200.

31. Bouvier D, Fournier M, Dauphin JB, Amat F, Ughetto S, Labbé A, Sapin V. Serum S100B determination in the management of pediatric mild traumatic brain injury. Clin Chem. 2012;58(7):1116-22.

32. Babl FE, Oakley E, Dalziel SR, Borland ML, Phillips N, Kochar A, Dalton S, Cheek JA, Gilhotra Y, Furyk J, Neutze J, Donath S, Hearps S, Molesworth C, Crowe L, Bressan S, Lyttle MD. Accuracy of clinician practice compared with three head injury decision rules in children: a prospective cohort study. Ann Emerg Med. 2018;71(6):703-10.

33. Bazarian JJ, Biberthaler $P$, Welch RD, Lewis LM, Barzo $P$, Bogner-Flatz V, Gunnar Brolinson P, Büki A, Chen JY, Christenson RH, Hack D, Huff JS, Johar S, Jordan JD, Leidel BA, Lindner T, Ludington E, Okonkwo DO, Ornato J, Peacock WF, Schmidt K, Tyndall JA, Vossough A, Jagoda AS. Serum GFAP and UCH1-L1 in prediction of absence of intracranial injuries on head CT (ALERT-TBI): a multicenter observational study. Lancet Neurol. 2018;17(9):782-9.

34. Astrand R, Unden J, Bellner J, Romner B. Survey of the management of children with minor head injuries in Sweden. Acta Neurol Scand. 2006; 113(4):262-6.

\section{Ready to submit your research? Choose BMC and benefit from:}

- fast, convenient online submission

- thorough peer review by experienced researchers in your field

- rapid publication on acceptance

- support for research data, including large and complex data types

- gold Open Access which fosters wider collaboration and increased citations

- maximum visibility for your research: over $100 \mathrm{M}$ website views per year

At BMC, research is always in progress.

Learn more biomedcentral.com/submissions 